\title{
Article
}

\section{Smart Core and Surface Temperature Estimation Techniques for Health-conscious Lithium-ion Battery Management Sys- tems: A Model-to-Model Comparison}

\author{
Sumukh Surya ${ }^{{ }^{*}}$, Akash Samanta ${ }^{2}$, Vinicius Marcis ${ }^{3}$, Sheldon S. Williamson ${ }^{4}$ \\ ${ }^{1}$ e-PowerTrain, KPIT, Bangalore 560103, India, sumukhsurya@gmail.com \\ ${ }^{2}$ Department of Applied Physics, University of Calcutta, Kolkata 700009, India, akashsamanta440@gmail.com \\ ${ }^{3}$ Department of Electrical, Computer and Software Engineering, Ontario Tech University, Oshawa, ON L1G \\ 0C5, Canada, vinicius.marcis@ontariotechu.net \\ ${ }^{4}$ Department of Electrical, Computer and Software Engineering, Ontario Tech University, Oshawa, ON L1G \\ 0C5, Canada, sheldon.williamson@uoit.ca \\ * Correspondence: sumukhsurya@gmail.com
}

\begin{abstract}
Estimation of core and surface temperature is one of the crucial functionalities of the lithium-ion Battery Management System (BMS) towards providing effective thermal management, fault detection and operational safety. While, it is impractical to measure core temperature using physical sensors, implementing a complex estimation strategy in on-board low-cost BMS is challenging due to high computational cost and the cost of implementation. Typically, a temperature estimation scheme consists of a heat generation model and a heat transfer model. Several researchers have already proposed ranges of thermal models having different levels of accuracy and complexity. Broadly, there are first-order and second-order heat capacitor-resistor-based thermal models of lithium-ion batteries (LIBs) for core and surface temperature estimation. This paper deals with a detailed comparative study between these two models using extensive laboratory test data and simulation study to access suitability in online prediction and onboard BMS. The aim is to guide whether it's worth investing towards developing a second-order model instead of a first-order model with respect to prediction accuracy considering modelling complexity, experiments required and the computational cost. Both the thermal models along with the parameter estimation scheme are modelled and simulated using MATLAB/Simulink environment. Models are validated using laboratory test data of a cylindrical 18650 LIB cell. Further, a Kalman Filter with appropriate process and measurement noise levels are used to estimate the core temperature in terms of measured surface and ambient temperatures. Results from the first-order model and second-order models are analyzed for comparison purposes.
\end{abstract}

Keywords: Electric Vehicles; Stationary Battery Energy Storage System; Battery Automated System; Online State Estimation; Thermal Modeling; First-order model; Second-order Model; Kalman Filtering

\section{Introduction}

Lithium-ion batteries (LIBs) have been extensively commercialized as a primary energy storage technology for electric vehicles (EVs), stationary energy storage in the smart grid system and several other consumer electronics. The primary dominating factors of LIBs over other energy storage technologies include high energy density, long lifespan, and declining cost [1-4]. However, from literature and practice, it is noticed that the performance of LIBs as well as the durability and reliability are significantly influenced by the operating temperature. Moreover, excessively high temperatures may cause thermal runaway, leading to fire, smoke, and other serious safety issues to the operators [5-7]. Therefore, the requirement of a battery management system (BMS) become indispensable for effective thermal management and safety of LIB system which essentially 
requires the accurate information of core and surface temperature of each cell [8,9] besides other important states such as state of charge (SOC) $[10,11]$ and state of health (SOH). Few other popular functions of an advanced BMS includes cell balancing [12,13], fault detection/diagnosis [14], and some other safety inspection functionalities. Several recent research studies highlighted that the accuracy of estimating cell SOC [15], SOH [16], and remaining storage capacity [17] depends on the accurate estimation of cell temperature as all these states are the function of temperature. Moreover, the Columbic efficiency of a cell is greatly affected by the cell temperature during the charging and discharging period. It is worthwhile to mention that the temperature distribution inside the cell is not uniform and the core temperature remains higher than the surface temperature during real-world application, especially under high charging and discharging current [18]. Typically, the difference between the core and surface temperature varies in the range of $5-10^{\circ} \mathrm{C}[19,20]$, however under high current loading with rapid load fluctuation it could be even more. Therefore, accurate information of core and surface temperature is essential to achieve effective thermal management system of LIB pack besides fault detection. While most of the existing temperature measurement techniques measure the surface temperature directly using physical sensors [21], the measurement of cell internal temperature is highly challenging using physical sensor. Moreover, installing physical sensors in each cell is not practically feasible form system cost, space and safety point of view as the high capacity battery pack used in EVs and grid-tied energy storage system consists of thousands of individual cells.

To sum up, accurate information of core temperature is undoubtedly serving as the essential basis for the thermal management and safety of LIB apart from SOC, SOH estimation whilst it is intractable to measure the core temperature using physical sensors. Therefore, a precise thermal model is crucial to accurate temperature estimation. Moreover, it should be easy to model and computationally inexpensive in order to be implemented in on-board BMS for online prediction of temperature. Several temperature estimation techniques have been proposed by researchers. Typically, a temperature estimation strategy consists of two models namely, a heat generation model and a heat transfer model [22]. The heat generation model takes physical measurement signals from a cell typically voltage, current to estimate the total heat generation during charging and discharging. Then the heat transfer model takes the estimated total heat quantity as model input to predict the temperature of that cell. Depending upon the modelling, it can estimate only core temperature (single-state) or both core and surface temperature simultaneously (two-state).

Broadly, heat generation models reported in the literature can be classified into three groups, Electrochemical model [23-26], data-driven empirical models [27-29] and equivalent circuit models (ECM) [30-32]. Few other researchers also grouped the heat generation model from the perspective of heat concentration. According to them, the heat generation model could be a concentrated model (all heat is generated at the core), distributed model (heat generated uniformly over the cell) [33] and heterogeneous model $[30,34]$ (due to temperature and current density gradient inside the cell). On the other hand, the heat transfer model can be grouped into Finite element analysis (FEA)-based models [32,35-38], lumped multi-node models [27,39-41], and heat capacitive-resistive models [42]. The lumped multi-node model and heat capacitive-resistive models are typically developed based on the analogy between thermal and electrical phenomena. It is seen that the electrochemical model can produce a very accurate heat generation value provided all model parameters are carefully tuned. However, the electrochemical models are highly complex and computationally expensive. The accuracy of data-driven empirical models highly depends on the experimentally acquired data. Collecting such high-resolution data is challenging and with the increase in data volume and the number of feature vectors, computational expenses also increase exponentially. On the other hand, ECM based estimation model can be designed suitable for online prediction and real-world application by establishing a balance between the computational cost and 
prediction accuracy. Therefore, ECM-based battery models are extensively used in real life for estimating heat generation in LIB. Further, as far as the heat transfer model is concerned, the heat capacitor-resistor models are easy to develop and computationally efficient compared to FEA-based methods and lumped parameter multi-node models. The FEA-based methods are highly accurate however with the expenses of high computational resources. Although the heat capacitor-resistance models usually ignore the detailed internal temperature gradient of a cell, its computational cost is very low. Moreover, if it can be engineered optimally the prediction accuracy will be adequate for the requirement of a real-world BMS. Therefore, heat capacitor-resistance model-based temperature estimation is the prime focus of this present study.

Researchers have proposed different kinds of heat capacitor-resistance models for the accurate and precise internal and surface temperature estimation of LIB. However, the major concern regarding the practical application of any model is its computational cost, the capability of online prediction and suitability for onboard BMS. Detailed model of LIB accounting for the thermal characteristics of different layers, modelling complexity and experimental data requirement is studied in the references [43-48]. The heat capacitor-resistance models use the analogy between thermal and electrical phenomena. Where heat capacity (thermal capacitance) and heat transfer coefficient (thermal resistance) are represented as electrical capacitor and resistor respectively [43]. So far, first-order model (one thermal energy storage element) and second-order model (two thermal energy storage elements) based thermal models were reported in the literature for temperature estimation. Second-order models are typically complex and require extensive experiments alongside the knowledge of domain experts during modelling. On the other hand, first-order models are easy to implement, computationally inexpensive and require very less experiments, thus widely used in real-life application. However, recently second-order models are extensively researched. Respective research studies developed thermal model and their prediction accuracy was assessed. However, a comparative study between the first-order and second-order model has not yet been assessed. Therefore, this research study focused on the comparative study to investigate and illustrate the fact whether it's worth investing in developing and implementing second-order thermal model for core and surface temperature estimation of LIB in terms of accuracy, modeling complexity, experimental requirement and practicability in on-board BMS. Extensive experiments are conducted for data collection and further the data is utilized for modeling, validation and comparison purposes. The strategy is to employ an ECM based heat generation model for both first-order and second-order thermal model to determine the total heat generation inside the cell. Thereafter, accumulate the temperature estimation results from each thermal model separately. Kalman Filter (KF) is used in both the cases to improve prediction performance. Then, compare the estimation results with the measured data to assess the modeling accuracy. Finally, compare the predicted results obtained from the models for the model-to-model comparison purpose. Moreover, parameter sensitivity analysis was not covered seldomly. Thus, it is considered in this study as well.

The remaining portion of the article is subdivided into another five sections for better readability, representation and understanding of the readers. First-order and Second-order thermal modelling of LIB and the respective temperature estimation strategy are presented in Section 2. The experimental setup and model parameter identification are discussed in Section 3. Temperature estimation using the fusion of first-order thermal model with KF and second-order thermal model with KF are described in Section 4. Section 4 also includes the comparative study between the first-order thermal model and second-order thermal model in terms of modelling complexity, practicality, the possibility of reverse calculating the surface or core temperature and vice-versa. Major findings and concluding remarks are drawn in the conclusion in Section 5. 


\section{Thermal Modeling and Temperature Estimation Strategy}

Commercially LIBs are available in many different form factors such as prismatic cells, pouch cells, and cylindrical cells. Among these, cylindrical cells are widely used in large-scale high-power applications. However, the cylindrical cell has worse thermal heat dissipation and the spiral format leads to a big thermal gradient between the core and surface. Therefore, thermal modelling of a 18650 cylindrical LIB cell is considered in this study considering the necessity of effective thermal management of cylindrical LIB. While, the properties, characteristics and parameters mentioned in this study are related to the 18650 LIB cell, a similar strategy can be used to easily construct a similar model for other form factors with suitable modification. The mathematical analysis and the fusion of KF with these thermal models for core and surface temperature estimation are presented in this section. The aim is to provide a guideline for selecting an appropriate thermal model for online prediction with an optimum computational cost suitable for onboard low-cost BMS. It is discussed in the introduction section that the temperature estimation model consists of one heat generation model and a heat transfer model where the heat generation model provides input to the heat transfer model. Therefore, the modelling strategy and mathematical analysis of the ECM-based heat generation model are considered here as well.

\subsection{Heat Generation Model}

Electric Circuit Model (ECM) [49] based thermal estimation model were reported by several researchers for estimating the total heat generation inside the LIB cell. A 1-RC (first-order) ECM is considered here in this study to quantify the total heat generation (Q). The 1-RC ECM of LIB is shown in Figure 1. The basic strategy used by any ECM-based heat generation model is to mathematically accumulate the heat generation from internal power losses that typically depend on the internal resistance and charging/discharging current level. Again, the heat generation depends on the cell SOC, current level and temperature as the internal resistances are the functions of these variables.

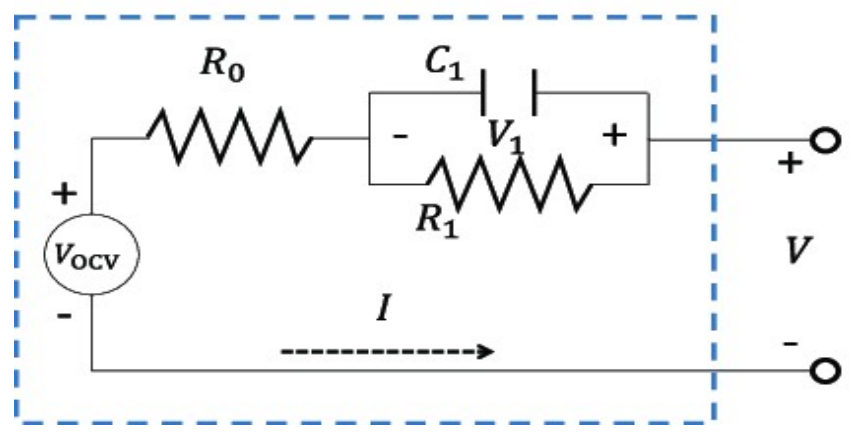

Figure 1. 1-RC ECM (Thevenin's equivalent) model of a LIB cell

Where Vocv is the cell open-circuit voltage, $\mathrm{V}$ is the terminal voltage, $\mathrm{R}_{0}$ is the steady-state DC series resistance, represents the electrolyte resistance on the lithium-ion transportation. Further, the short transient response is caused by the lithium-ion flow in the solid electrolyte interphase layer and the anode electrode is represented by polarization resistance $\left(R_{1}\right)$ and capacitance $\left(C_{1}\right)$ respectively. These $R_{1}$ and $C_{1}$ appear only during the transient period [50]. To capture the high-frequency transient response during the fast charging/discharging situation, higher-order models may require [51] with higher computational resources. A 1-RC battery model is considered in this study due to its optimum performance, ease of modelling, low computational cost, and adequate accuracy when compared to other higher order RC models [52]. Further, online determination of heat generation inside LIB with these higher-order models is challenging due to compu- 
tational cost. Here, Bernardi et al. [53] developed a simplified equation for LIB heat generation calculation which is suitable for online prediction over other computationally expensive methods such as constant heat generation rate [54], curve fitting technique [55], and Joule's Law [56] based methods. The governing equation for $Q$ as developed by Bernardi et al. is shown in Equation 1.

$$
Q=I\left(V-V_{O C V}\right)
$$

The equations parameters also function of charging/discharging condition, SOC and temperature that are estimated using the ECM. Finally, the value of the Q, obtained from Equation 1 is used as one of the inputs to the first-order and second-order thermal model for temperature estimation which is discussed in the following section.

\subsection{First Order Thermal Modelling}

\subsubsection{Mathematical Analysis of First-order Thermal Model}

Now for the first-order model, like several other researchers [43] the surface temperature is considered constant throughout the surface of the cell, heat transport is only along the radial direction meaning the lateral surface temperature is considered the same as cell terminal temperature. Further, regarding heat transfer, only heat conduction from core to surface is considered. Heat exchange between surface and ambient by convection is not considered.

The first-order thermal model is depicted in Figure 2. Where, thermal parameters, that is, heat capacity of the core is represented by $C_{p}(J / K)$, heat transfer resistance inside

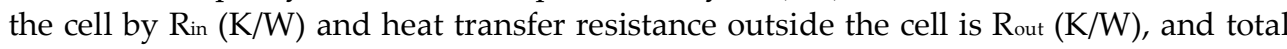
quantity of heat liberated concentrated from the core is represented by $Q(J)$. The unit of each respective quantity is mentioned in the parenthesis. The temperature of core, surface, and ambient is mentioned by $\mathrm{T}_{\mathrm{c}}, \mathrm{T}_{\mathrm{s}}$ and $\mathrm{T}_{\mathrm{amb}}$ respectively measured in $\mathrm{K}$. Core temperature at node $T_{c}$ and surface temperature at node $T_{s}$ can be monitored using this model thus this type of model are also referred to as two-node or two-state thermal model [22,57].

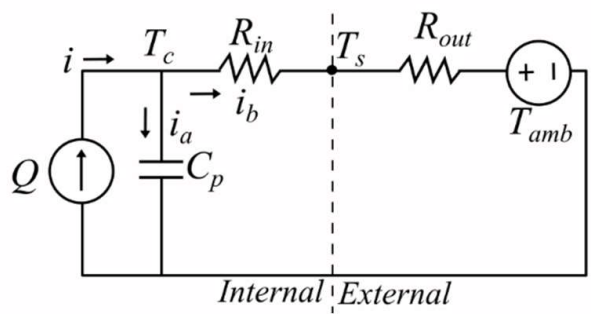

Figure 2. First-order equivalent circuit thermal model of LIB

The heat capacitor-resistor model uses the analogy between the thermal and electrical systems as discussed in the introduction section. Thus, for mathematical analysis, the heat transfer rate is represented by electrical current (i) and the branch currents are represented by $i_{a}, i_{b}$ in the respective branch as shown in Figure 2. Therefore, the governing equation of the model can be derived by applying Kirchhoff's Current Law (KCL) at the $\mathrm{T}_{\mathrm{c}}$ node. The current balance equation at node $\mathrm{T}_{\mathrm{c}}$

$$
i=i_{a}+i_{b}=Q
$$

Now, by rewriting Equation 2 in terms of thermal parameters, Equation 3 can be found as; 


$$
Q=C_{p} \frac{d T_{c}}{d t}+\frac{T_{s}-T_{c}}{R_{\text {in }}}+\frac{T_{a m b}-T_{s}}{R_{\text {out }}}
$$

Re-arranging Equation 3,

$$
C_{p} \frac{d T_{c}}{d t}=Q+\frac{T_{s}-T_{c}}{R_{\text {in }}}+\frac{T_{a m b}-T_{s}}{R_{\text {out }}}
$$

Finally, the value of $\mathrm{T}_{\mathrm{c}}$ can be calculated by integrating Equation 4 with respect to the total heat transfer time while the values of $\mathrm{T}_{\mathrm{s}}$ and $\mathrm{T}_{\mathrm{amb}}$ are known. While $\mathrm{T}_{\mathrm{amb}}$ can be easily measured by employing only one temperature sensor, the measurement of $\mathrm{T}_{\mathrm{s}}$ with physical sensors in a high-power LIB pack is challenging. Therefore, the alternative solution is to estimate the surface temperature using a temperature estimation scheme. One such estimation scheme is also proposed in reference [8] that estimates $\mathrm{T}_{\mathrm{s}}$ from known $\mathrm{T}_{\mathrm{c}}$.

\subsubsection{KF for First Order Thermal Model}

$\mathrm{KF}$ is used to estimate and predict an unknown parameter from known parameters. The state model for a KF is shown in [43,58] and the first-order model was shown in [59]. However, the mathematical model for KF was not presented. Assuming the state as $T_{c, t}$, output as $T_{s, t}$, and inputs as $Q$ and $T_{a m b}$. The state-space matrices are derived by linearizing Equation 4 in the discrete domain. A linearized version of Equation 4 is shown in Equation 5.

$$
T_{c, t}-T_{c, t-1}=\frac{Q_{t-1}}{C c}+\frac{T_{s, t-1}-T_{c, t-1}}{C_{c} R_{c}}+\frac{T_{a m b, t}-T_{s, t-1}}{C_{c} R_{u}}
$$

As shown in [8], small changes in $T_{s}$ can be neglected. Hence $T_{s, t-1}=0$

$$
T_{c, t}=\frac{Q_{t-1}}{C c}+T_{c, t-1}\left(1-\frac{1}{C_{c} R_{c}}\right)+\frac{T_{a m b, t-1}}{R_{u} C_{c}}
$$

The transfer matrices of the KF-based temperature estimation model can be found by reducing Equation 6 in the form of state models as shown in Equation 7 to Equation 9.

$$
\begin{aligned}
& \text { Hence, } \mathrm{A}=\left[1-\frac{1}{C_{c} R_{c}}\right. \\
& \mathrm{B}=\left[\begin{array}{ll}
\frac{1}{C_{c}} & \frac{1}{C_{c} R_{u}}
\end{array}\right] \\
& \mathrm{C}=\mathrm{D}=0
\end{aligned}
$$

\subsection{Second-Order Thermal Modelling}

\subsubsection{Mathematical Analysis of Second-Order Thermal Model}

The condition of non-uniform $\mathrm{T}_{\mathrm{s}}$ and heat transport in the radial direction through conduction from core to surface are also considered during the second-order thermal modelling. Additionally, the heat exchange between the surface and ambient is considered in the second-order model which was not included in the first-order model. Only 
convective heat exchange between the cell surface and ambient is only considered here. Therefore, in addition to the thermal properties of the first-order model, the thermal capacitance of cell case $\left(C_{s}\right)$ is also considered. The resulting equivalent circuit of the second-order thermal model using heat capacitor-resistor is shown in Figure 3 similar to several other studies [57,60-62].

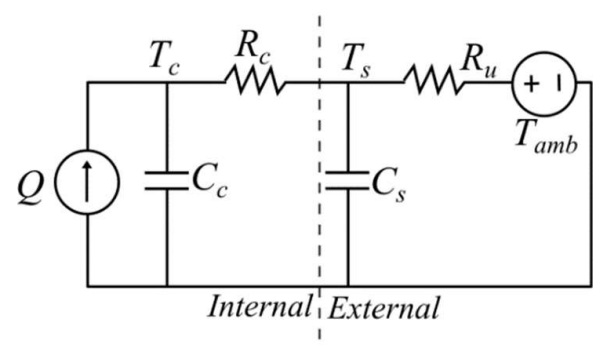

Figure 3. Second-order equivalent circuit thermal model of LIB

Q needs to be estimated for the same ECM-based strategy mentioned in section 2.1. To derive the mathematical analysis of the second-order thermal model, heat balance analysis in the core and surface is performed. The heat balance equation at the core and surface is represented in Equations 10 and Equation 11 respectively [60].

$C_{c} \frac{d T_{c}}{d t}=Q+\frac{T_{s}-T_{c}}{R_{c}}$

$C_{s} \frac{d T_{s}}{d t}=\frac{\left(T_{a m b}-T_{s}\right)}{R_{u}}-\frac{\left(T_{s}-T_{c}\right)}{R_{c}}$

\subsubsection{KF for Second-order Thermal Model}

$\mathrm{T}_{\mathrm{c}}$ could be estimated by re-arranging the coupled Ordinary Differential Equations (ODEs) of the second-order thermal model. Since the thermal model had two thermal energy storage parameters $\left(C_{c}\right.$ and $\left.C_{s}\right)$, two governing equations are used to estimate $T_{c}$ in terms of measured $\mathrm{T}_{\mathrm{s}}$ and $\mathrm{T}_{\mathrm{amb}}$.

$\mathrm{A}=\left[1-\frac{1}{C_{c}\left(R_{c}+R_{u}\right)}\right]$

$\mathrm{B}=\left[\begin{array}{ll}\frac{1}{C_{c}} & \frac{1}{C_{c}\left(R_{c}+R_{u}\right)}\end{array}\right]$

$\mathrm{C}=\left[\frac{R_{u}}{R_{c}+R_{u}}\right]$

$\mathrm{D}=\left[\begin{array}{ll}0 & \frac{R_{c}}{R_{c}+R_{u}}\end{array}\right]$

It should be noted that in the Equation 4 and Equation 10, $C_{p}=C_{c}, R_{i n}=R_{c}$ and $R_{\text {out }}=R_{u}$. The state model of the KF and its governing equations are is shown in equations 16 and 17 [63-65]. 


$$
\begin{aligned}
& X_{k}=A_{k-1} X_{k-1}+B_{k-1} U_{k-1}+W_{k-1} \\
& Y_{k}=C_{k} X_{k}+D_{k} U_{k}+V_{k}
\end{aligned}
$$

Where $X_{k}$ is the state of the system $\left(T_{c, t}\right), Y_{t}=$ output of the system $\left(T_{s, t}\right), u_{k}$ is the input to the system $\left(\left[\mathrm{T}_{\mathrm{amb}, t} \mathrm{Q}\right]^{\mathrm{T}}\right), \mathrm{t}=$ present state of the system and $\mathrm{t}-1=$ previous state of the system. Rewriting Equations 10 and Equation 11 in the discrete-time domain to determine the state-space matrices that are shown in Equations 16 and 17 and the resulting state-space matrices are shown in Equation 12 to Equation 15 based on the guidance provided in reference [66]. Worth noting that the $C_{c}, R_{c}$, and $R_{u}$ in the second-order thermal model are the same as $C_{p}$, $R_{\text {in, }}$ and Rout of the first-order model respectively.

\section{Experimental Analysis for Thermal Model Parameterization}

An automated battery testing system is the best option especially for LIB as LIB cells are highly sensitive to voltage, current, temperature and other environmental uncertainties. Therefore, an in-house "Battery Automated System (BAS)" was previously developed by the research group of Smart Transportation Electrification and Energy Research (STEER). The setup was used to invent the constant temperature constant current (CT-CV) charging technique $[67,68]$ and several other prominent research studies in the BMS domain $[2,4,8]$. The BAS is an experimental setup with a fully programmable test environment control and data acquisition system. A schematic layout of the BAS is shown in Figure 4. The experimental data is then used for the parameter estimation of ECM and thermal modelling, model validation, and model-to-model comparison purposes. Interested readers are invited to these articles $[2,4,8,67,68]$ for more details about the experimental setup. However, a brief overview of the experimental setup and test conditions are also mentioned in this section for a quick reference to the readers. The basic idea is to identify the input parameters of the thermal model, that is, heat capacity and heat transfer coefficients through a steady-state analysis as well as transient experiments based on the non-linear least square algorithm. LIB cell is tested at three different temperatures where the internal battery temperature is raised using standard current pulses that are within the permissible limit specified on the manufacturer datasheet to ensure no capacity fade occurred during testing.

\subsection{Experimental Setup}

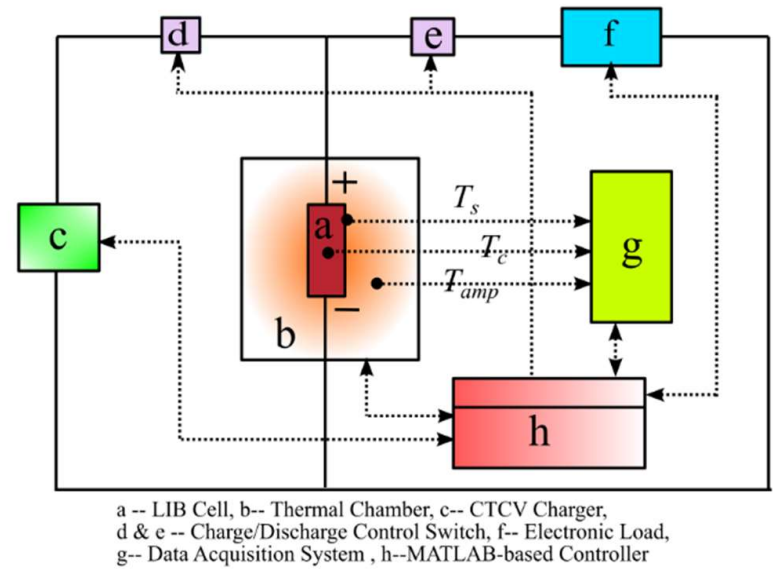

Figure 4. Schematic layout of the Battery Automated System (BAS)

Battery testing is performed of an 18650 NMC (Lithium Nickel Manganese Cobalt Oxide) LIB, manufactured by LG Chem. Detailed specifications of the cell as provided by the manufacturer are mentioned in Table 1. A programmable power supply (Model: 
E36313A) from Keysight and a programmable electronic load (Model: BK8601) from B\&K Precision are used for charging and discharging the battery with a predefined charging/discharging current profile. Further, a programmable temperature chamber is used to maintain the $\mathrm{T}_{\mathrm{amb}}$ based on a predefined setpoint. Finally, to control the BAS a MATLAB script-based program is used. A programmable data acquisition system (DAQ) (model DPM66204) from Chroma is used to collect the cell voltage, current and temperature data. Different current profiles at three different ambient temperatures $\left(\mathrm{T}_{\mathrm{amb}}=273 \mathrm{~K}\right.$ $\left(0{ }^{\circ} \mathrm{C}\right), 293 \mathrm{~K}\left(20^{\circ} \mathrm{C}\right)$, and $\left.323 \mathrm{~K}\left(50{ }^{\circ} \mathrm{C}\right)\right)$ are used for charging and discharging experiments. Finally, a non-linear least square algorithm is used for online parameter estimation for developing the ECM and thermal model as demonstrated by Surya et al. [60]. All the model components are designed in MATLAB using three-dimension interpolated Look-Up-Tables where feature vectors are SOC, Ibat and Tamb. The heat generation model and the first-order and second-order thermal model are also developed in MATLAB/Simulink and Simscape environment. Finally, an extensive simulation study is conducted to collect the simulated core and surface temperature data for further analysis. Simulation results are used for model validation as well as for model-to-model comparison between the first-order and second-order thermal models. The core temperature $\left(\mathrm{T}_{\mathrm{c}}\right)$ is estimated using a KF for various patterns of currents that are within the permissible limit specified on the manufacturer datasheet to ensure no capacity fade occurred during testing.

Table 1. Specifications of 18650 LIB Cell Under Test

\begin{tabular}{cc}
\hline Specification Name & Values \\
\hline Manufacturer and Model & LG Chem/ INR18650HG2 \\
Cell Form Factor & Cylindrical (18650) \\
Chemistry & Lithium Nickel Manganese Cobalt Oxide \\
& $($ LiNiMnCoO 2$)$ \\
Nominal Voltage & $3.6 \mathrm{~V}$ \\
Nominal Capacity & $3 \mathrm{Ah}$ \\
Standard Charging (CC-CV) & $1.5 \mathrm{~A}, 4.2 \mathrm{~V}$, Cut-off: $50 \mathrm{~mA}$ \\
Fast Charging (CC-CV) & $4.0 \mathrm{~A}, 4.2 \mathrm{~V}$, Cut-off: $100 \mathrm{~mA}$ \\
Discharging Condition & 20A (Max. Current), $2.5 \mathrm{~V}$ (Cut Off Voltage) \\
Operating Temperature & Charge: 0 to $50^{\circ} \mathrm{C}$, Discharge: -30 to $60^{\circ} \mathrm{C}$ \\
Pack Weight & 48 g \\
\hline
\end{tabular}

\section{Results and Discussion}

The intention of this research study is three folds towards addressing the prime concern of this study, that is, whether it's worth developing a second-order model instead of a first-order model for online temperature prediction by low-cost onboard BMS. Firstly, to develop a first-order and second-order thermal model utilizing battery test data and MATLAB-based online parameter estimation. Secondly, simulate the temperature profile of the cell using the first-order and second-order thermal models subjected to different current profiles. The intention is to investigate the impact of charging/discharging current on the core and surface temperature of the cell. Thirdly, compare the estimation results obtained from the first-order and second-order models. All simulations are carried out in the MATLAB-Simulink environment where a fixed solver and an appropriate step time [59] are used. Initially, simulation is done without employing a KF to deduce the baseline analysis. Figure 5 shows the current profile used for the base-case analysis and Figure 6 shows the plots of estimated $T_{c}, T_{s}$ and the measure $T_{a m b}$. 
It is observed that $T_{c}$ and $T_{s}$ closely follow the current profile and $T_{c}>T_{s}>T_{a m b}$ which is as per the expectation and confirms the modelling accuracy.

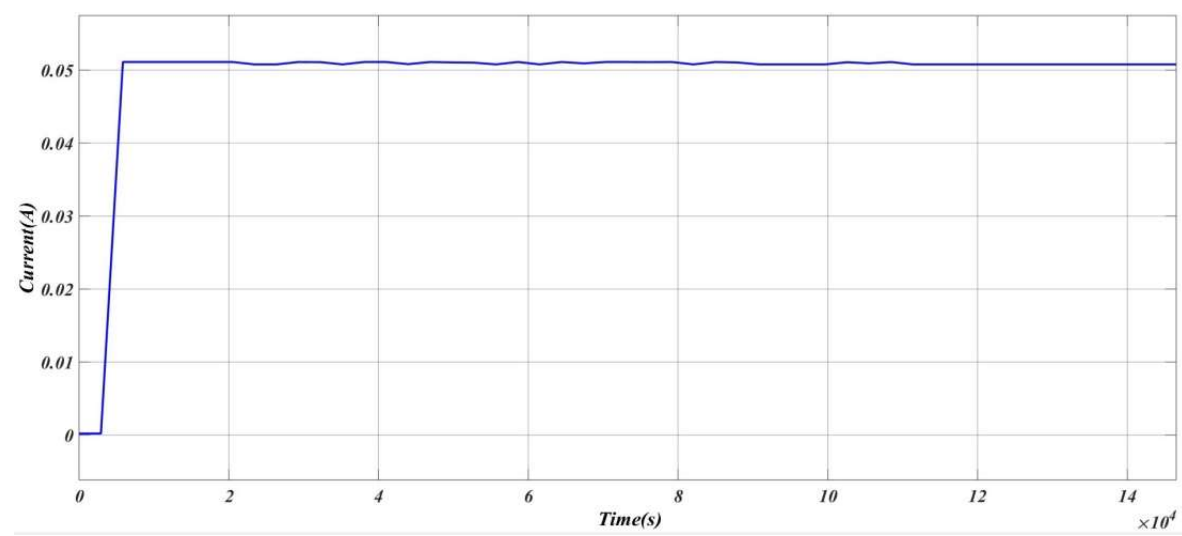

Figure 5. Pattern of the discharging current applied to the cell

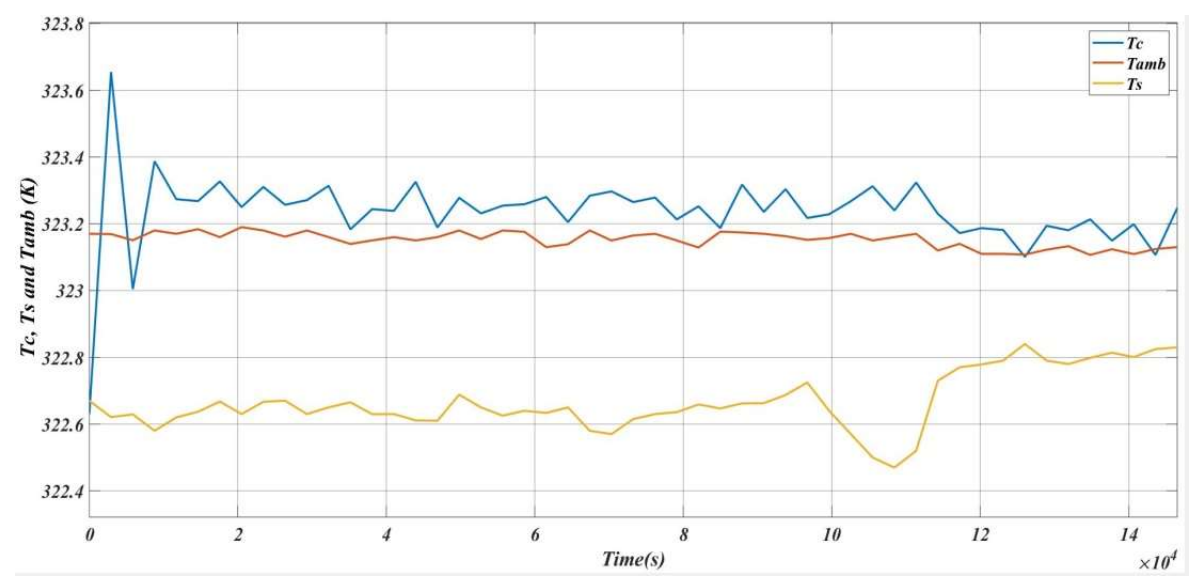

Figure 6. The plot of $\mathrm{T}_{\mathrm{c}}, \mathrm{T}_{\mathrm{s}}$ and $\mathrm{T}_{\mathrm{amb}}$ without using $\mathrm{KF}$

In the subsequent sections, firstly, $\mathrm{T}_{\mathrm{c}}$ is estimated using the combined first-order thermal model and KF for three different current profiles and ambient temperature that are illustrated in Case 1, Case 2 and Case 3 respectively. Secondly, a similar study is also conducted for the second-order model and finally, compared the results. All experiments are carried out with different current profiles as per manufacturer recommendation to ensure no battery health degrade [58]. In all cases, the initial currents are kept high for rapid charging of the cell.

\subsection{Case 1: $\operatorname{Tamb}_{a}=293 \mathrm{~K}\left(\left(20^{\circ} \mathrm{C}\right)\right.$}

At first, $T_{c}$ is initialized to $T_{s}$ in the simulation as initially, the cell is in a thermal equilibrium state. The temperature of the thermal chamber $\left(\mathrm{T}_{\mathrm{amb}}\right)$ is set to $293 \mathrm{~K}\left(20^{\circ} \mathrm{C}\right)$ and a very low value of discharging current is applied to see the core and surface temperature rise. The current pattern used in Case 1 is shown in Figure 7 and the plot of estimated $T_{c}$ and measured $T_{s}$ is shown in Figure 8 whereas the difference between the estimated $T_{c}$ and measured $T_{s}$ is shown in Figure 9. It is observed that the $T_{c}$ and $T_{s}$ closely followed the current pattern and the maximum difference between estimated $\mathrm{T}_{\mathrm{c}}$ and measured $T_{s}$. is noted as $6.8 \mathrm{~K}$. Whilst, it is also noticed that for all time $T_{c}>T_{s}$ and the maximum difference between occurred when the current is at its peak. 


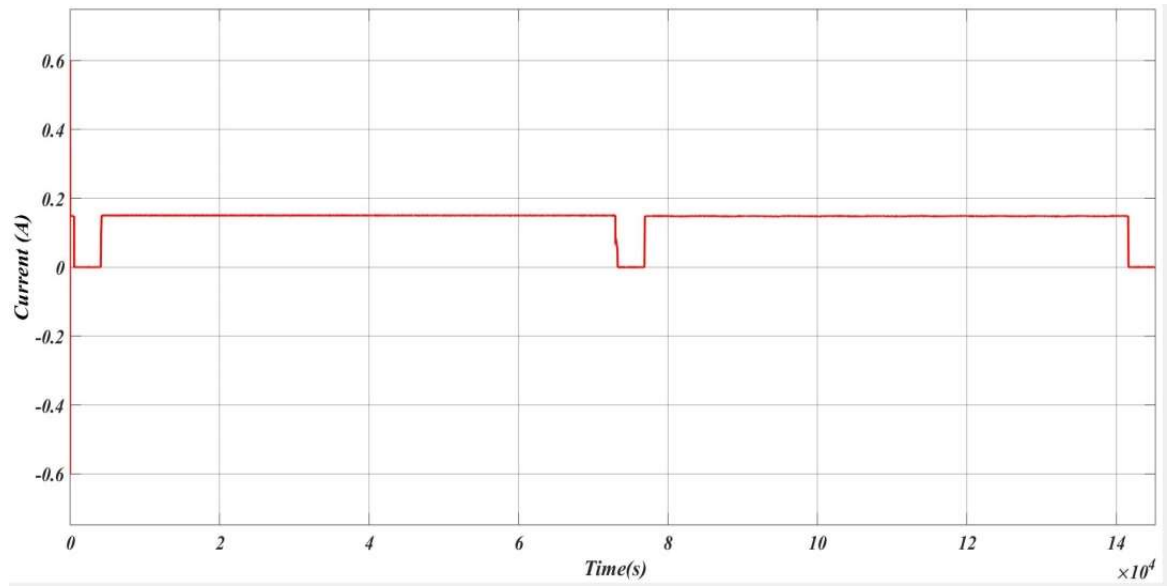

Figure 7. Pattern of the discharging current applied to the cell

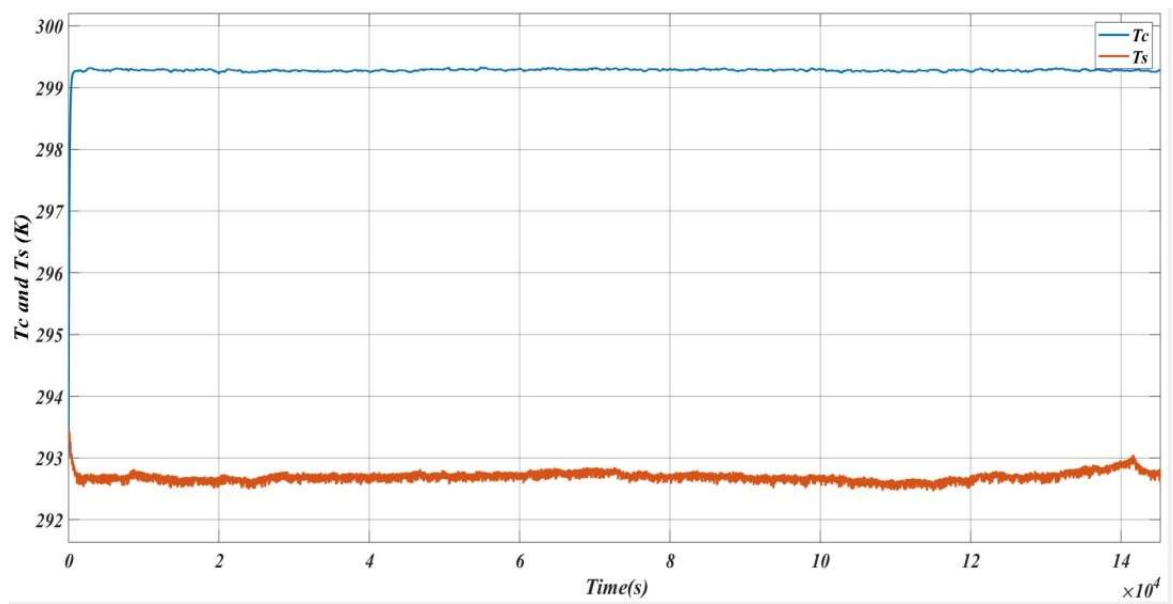

Figure 8. Plot of the estimated $\mathrm{T}_{\mathrm{c}}$ and measured $\mathrm{T}_{\mathrm{s}}$

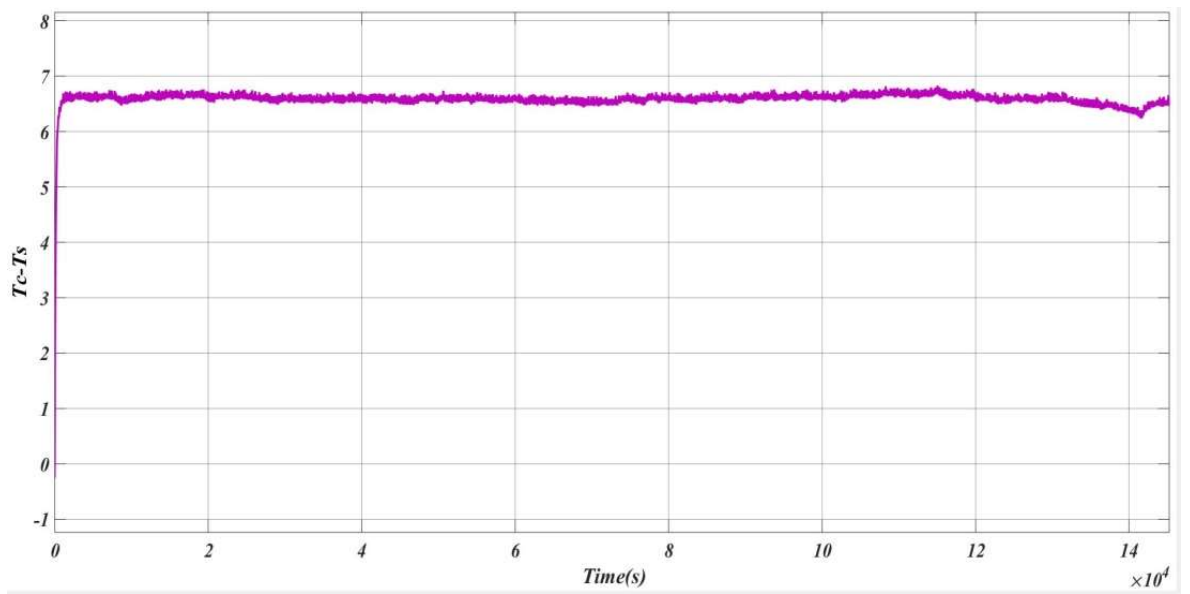

Figure 9. Variation of the difference between the estimated $T_{c}$ and measured $T_{s}$ 
In the second phase of the experiments, the temperature of the thermal chamber $\left(\mathrm{T}_{\mathrm{amb}}\right)$ is set to $323 \mathrm{~K}\left(50^{\circ} \mathrm{C}\right)$. The current pattern used in Case 2 is shown in Figure 10. Similar to Case $1, \mathrm{~T}_{\mathrm{c}}$ is initialized to $\mathrm{T}_{\mathrm{s}}$ during the simulation here as well. The estimated $\mathrm{T}_{\mathrm{c}}$ and measured $\mathrm{T}_{\mathrm{s}}$ are shown in Figure 11. It is observed that the temperatures closely followed the current pattern here also. The maximum difference between $T_{c}$ and measured $T_{s}$ is noticed as $7 \mathrm{~K}$. The plot of the difference between the estimated $T_{c}$ and measured $\mathrm{T}_{\mathrm{s}}$ is shown in Figure 12. Similar observations like Case 1 are also interred here in Case 2 regarding $\mathrm{T}_{\mathrm{c}}$ and $\mathrm{T}_{\mathrm{s}}$.

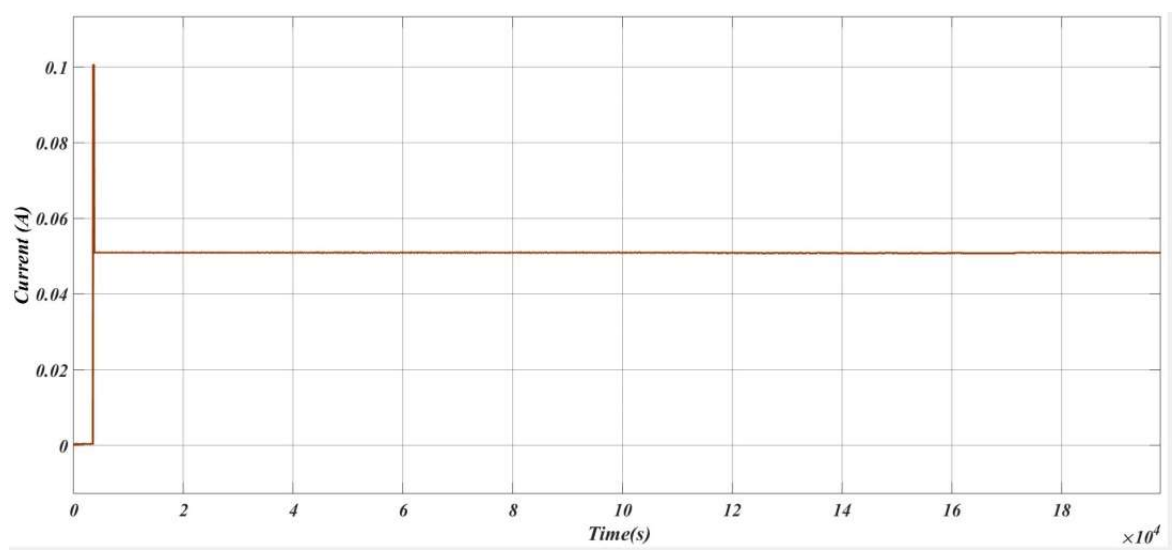

Figure 10. Pattern of the discharging current applied to the cell

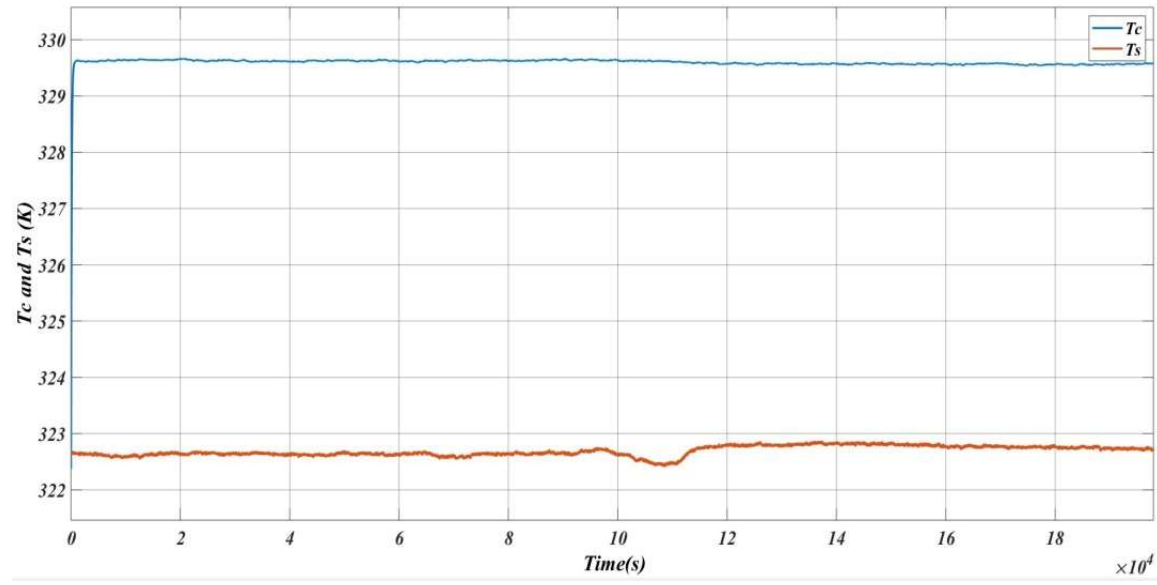

Figure 11. Plot of the estimated $T_{c}$ and measured $T_{s}$ 


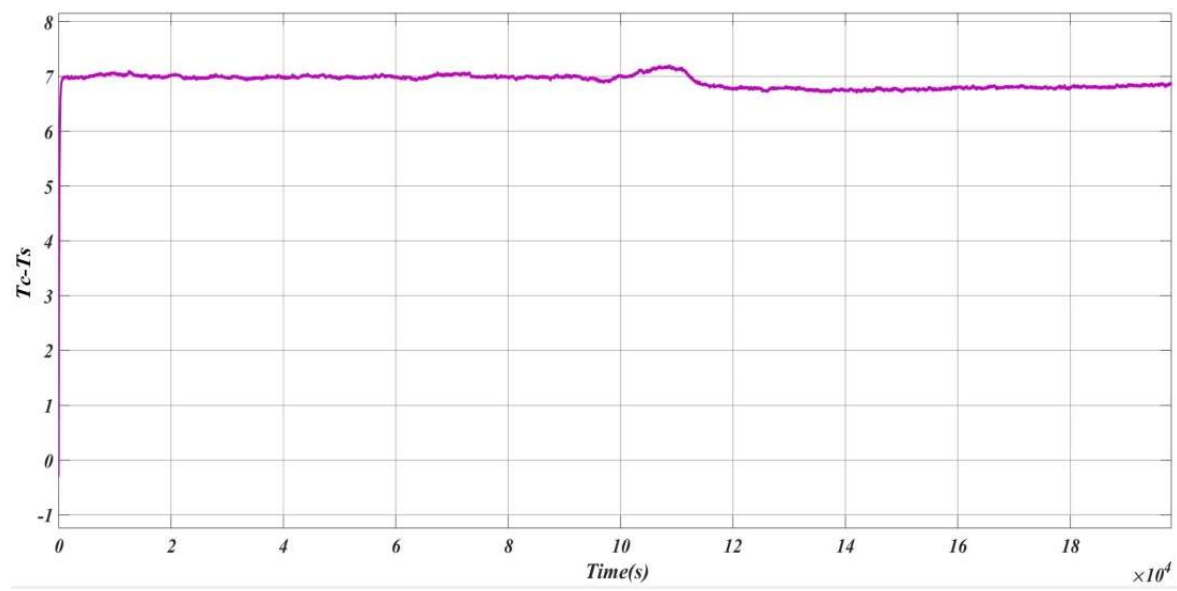

Figure 12. Variation of the difference between the estimated $T_{c}$ and measured $T_{s}$

\subsection{Case 3: $\mathrm{T}_{a m b}=273 \mathrm{~K}\left(0^{\circ} \mathrm{C}\right)$}

During Case 3, the temperature of the thermal chamber $\left(\mathrm{T}_{\mathrm{amb}}\right)$ is set to $273 \mathrm{~K}\left(0{ }^{\circ} \mathrm{C}\right)$ and $T_{c}$ is set equal to $T_{s}$. The pattern of discharging current applied to the battery is shown in Figure 13. Figure 14 shows the estimated $T_{c}$ and measured $T_{s}$. Figure 15 shows the difference between the estimated $\mathrm{T}_{\mathrm{c}}$ and measured $\mathrm{T}_{\mathrm{s}}$. It can be noticed from Figure 14 that at the beginning the magnitude of $\mathrm{T}_{\mathrm{c}}$ and $\mathrm{T}_{\mathrm{s}}$ are very large. This is due to the high value of discharging current during this period. It is also observed that the temperature rise is a slow process due to the presence of thermal resistances ( $R_{u}$ and $R_{c}$ ). The temperature difference increased as the value of discharge current increased. Therefore, it can be inferred from these observations is that the temperature rise closely follows the current through the battery and the rate of rising of $\mathrm{T}_{\mathrm{c}}$ is the same as $\mathrm{T}_{\mathrm{s}}$ for a low value of current. However, for higher values of current the rise in $T_{c}$ is much higher than $T_{s}$. From these observations, it is evidenced the importance of accurate core and surface temperature estimation alongside the requirement of effective and efficient thermal management to maintain $\mathrm{T}_{\mathrm{c}}$ under the safe operating limit.

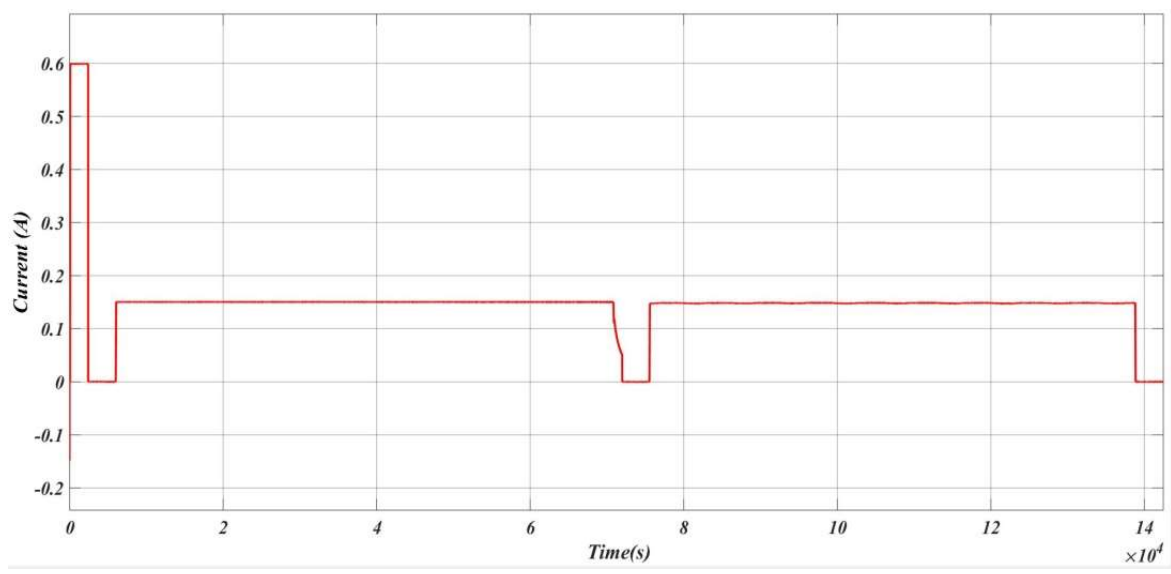

Figure 13. Pattern of the discharging current applied to the cell 


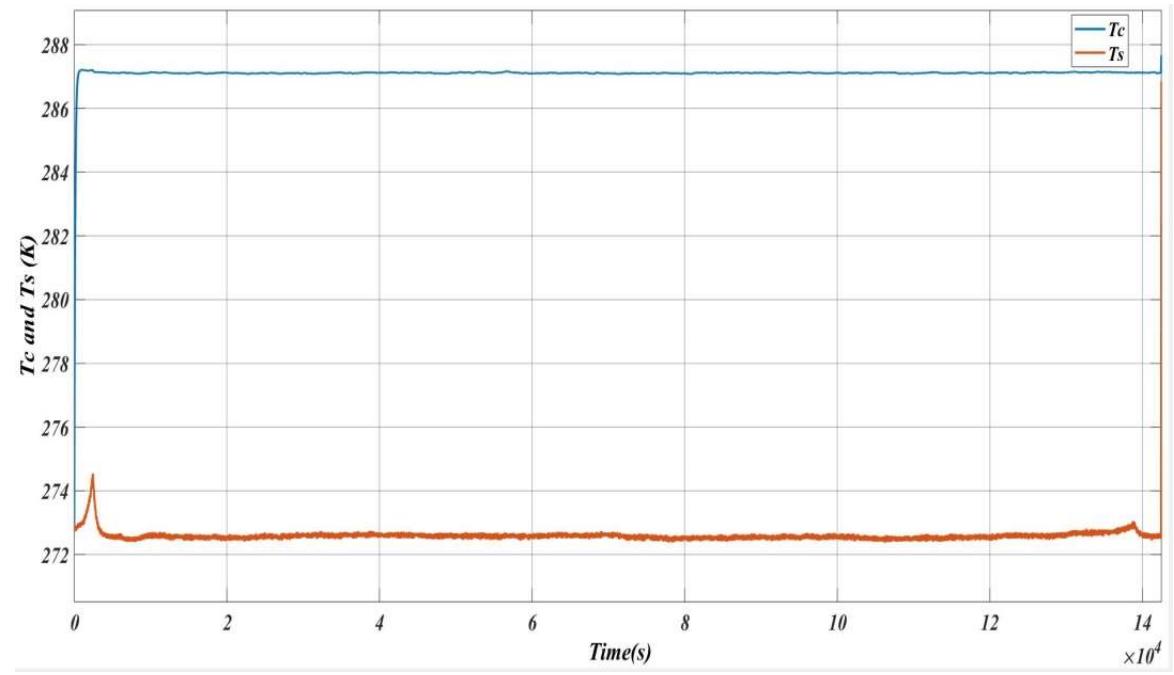

Figure 14. Plot of the estimated $\mathrm{T}_{\mathrm{c}}$ and measured $\mathrm{T}_{\mathrm{s}}$

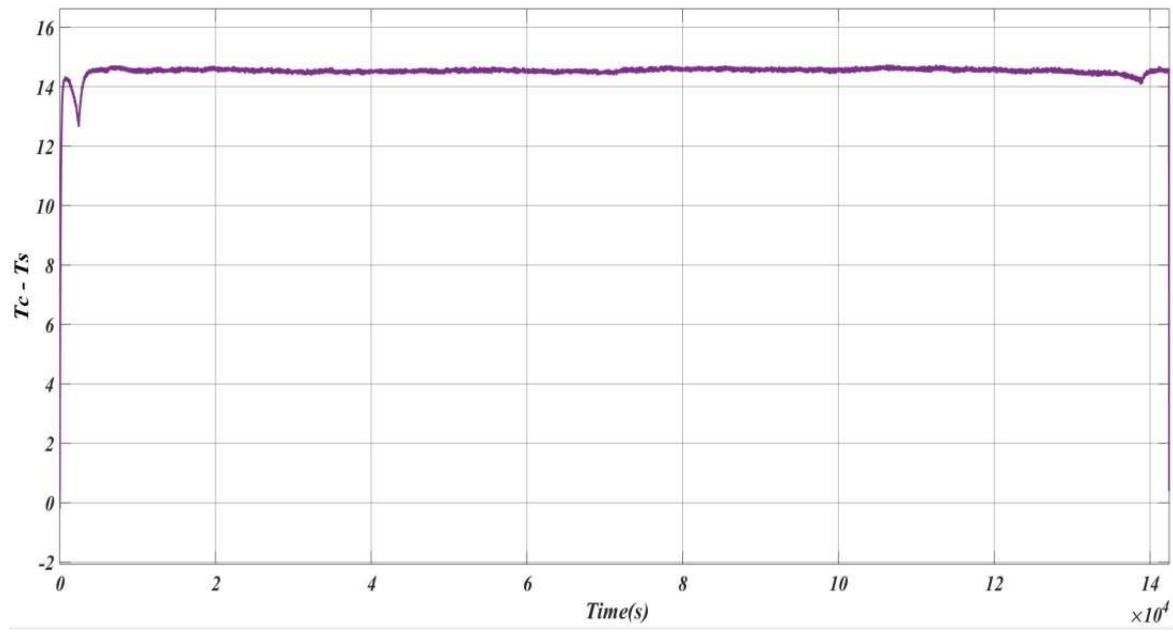

Figure 15. Variation of the difference between the estimated $\mathrm{T}_{\mathrm{c}}$ and measured $\mathrm{T}_{\mathrm{s}}$

\subsection{Comparison between First-order and Second-order Thermal Models}

This section deals with the comparative analysis between the first-order and second-order thermal based on the estimation accuracy, parameter identification, experimental test requirement, and suitability for onboard low-cost BMS. To compare the models, the same values of thermal parameters, current, $\mathrm{T}_{\mathrm{s}}, \mathrm{T}_{\mathrm{amb}}$ and $\mathrm{Q}$ are injected into the thermal models. Similar current profiles as used in Case 1, Case 2 and Case 3 of the first-order model are also applied to the second-order thermal model. Heat generation is calculated using the same 1-RC ECM as used in the first-order model. Finally, the estimated $T_{c}$ profiles obtained from the first-order and second-order thermal models are compared to analyze the prediction accuracy of these models. Figure 16 shows the current profile used for the comparative study whereas Figures 16 and Figure 17 depict the difference in $T_{c}$ and $T_{s}$ obtained from the first-order and second-order thermal model respectively. 


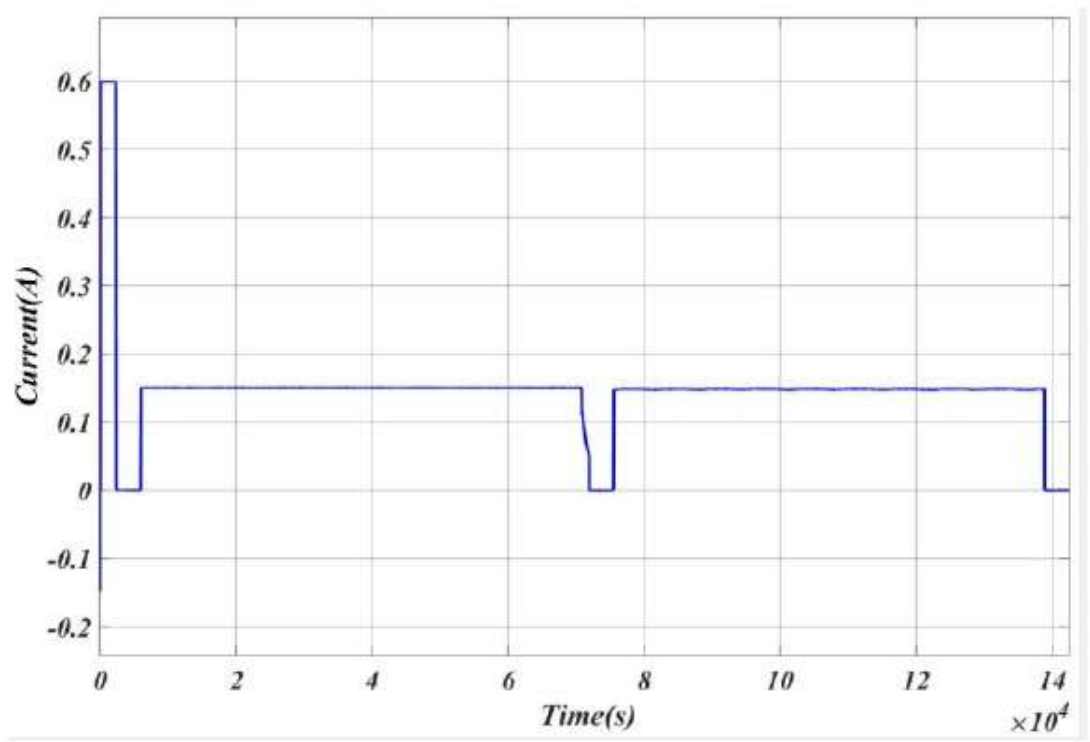

Figure 16. Pattern of the discharging current applied to both the models

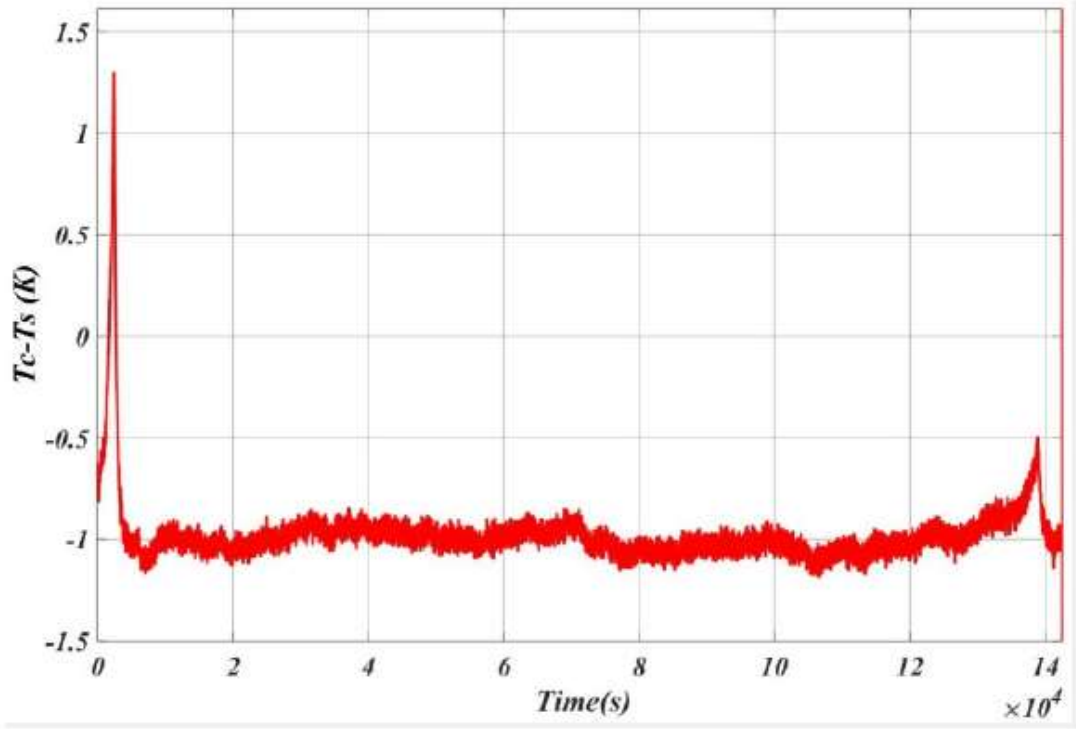

Figure 17. Difference between $\mathrm{T}_{\mathrm{c}}$ and $\mathrm{T}_{\mathrm{s}}$ obtained from second-order thermal model 


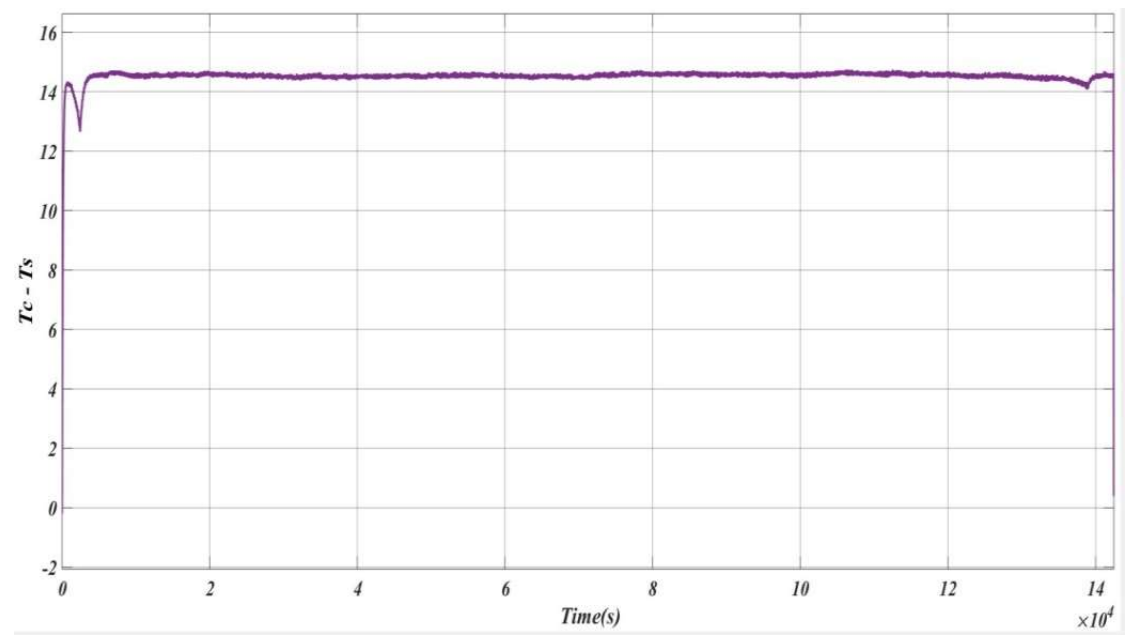

Figure 18. Difference between $T_{c}$ and $T_{s}$ obtained from the first-order thermal model

It is observed that the difference in temperatures is larger in the first-order thermal model due to the change in $T_{c}$ and not $T_{s}$. This is because the decoupling between $T_{s}$ and $T_{c}$ seen in Equation 3. Moreover, while comparing Equations (7), (8), and (9) with Equations (12), (13) and (14) it is noticed that the output parameter $\mathrm{T}_{\mathrm{s}}$ in KF showed no dependence on the state $T_{c, t-1}$ which is also a major reason behind the estimation error in case of the first-order model. Further, references [58] and [43] demonstrated that $C_{c}$ and $R_{u}$ of the second-order thermal model have a significant effect on $T_{c}$. Since these parameters are not present in the $\mathrm{C}$ and $\mathrm{D}$ matrices of the first-order model, a large increase in $T_{c}$ was observed. The thermal parameter sensitivity analysis as conducted in references $[58,60]$ also confirmed the same reason behind the error in temperature estimation by the first-order thermal model. It is found that the error between $T_{s}$ and $T_{c}$ is increased if the discharge current increased. Hence, for currents having dynamic changes, $T_{c}$ estimation using the first-order model provides large error than the second-order model. Further, $\mathrm{C}_{\mathrm{c}}$ contributes only to the transient part of $T_{c}$. However, with small changes in $R_{c}$ and $R_{u}$, a large variation in $T_{c}$ is also observed. The modelling complexity, experimental requirement and computational expenses in the used second-order model are not considerably high compared to the first-order model considered here. A tradeoff between the modelling complexity and accuracy requirement suggests the implementation of a second-order model is worth for smart BMS especially for high-power applications of LIB.

\section{Conclusions}

This paper deals with the $T_{c}$ estimation of Li ion 18650 cell using Kalman Filter. This estimation provides effective thermal management, state estimations, operational safety and the longer useful life of LIB. Initially, a detailed discussion regarding the importance of core and surface temperature sestimation is presented followed by a review of the state-of-the-art temperature estimation strategies and thermal modelling of LIB. Equivalent circuit model (ECM) of LIB-based heat generation model and heat capacitor-resistor-based thermal models are developed in MATLAB/Simulink environment. Regarding heat capacitor-resistor-based thermal modelling, one first-order and one second-order thermal model are developed and validated using laboratory experimental data. Further, extensive simulation studies are conducted to demonstrate the influence of battery current and ambient temperature on the core and surface temperature of the LIB cell. The heat transfer equation for a first-order and second-order thermal model are derived, modelled and simulated. Kalman Filtering with appropriate process and measurement noise levels is also used to estimate core temperature $\left(T_{c}\right)$ in terms of measured surface $\left(T_{\mathrm{s}}\right)$ and ambient temperature ( $\left.\mathrm{T}_{\mathrm{amb}}\right)$. Finally, these results are compared to access 
the prediction accuracy of these models. The difference between the core and surface temperatures is noticed as approximately $7 \mathrm{~K}$ to $8 \mathrm{~K}$ in the first-order model whereas only about $1 \mathrm{~K}$ to $2 \mathrm{~K}$ in the second-order thermal model. $\mathrm{T}_{\mathrm{s}}$ showed no dependence on $\mathrm{T}_{\mathrm{c}}$ in the first-order thermal model. Further, the output parameter, $\mathrm{T}_{\mathrm{s}}$ in $\mathrm{KF}$ showed no dependence on the state $T_{c, t-1}$ which is also a major reason behind the estimation error in the case of the first-order model. The thermal capacitance of core $\left(C_{c}\right)$ and resistances $\left(R_{u}\right)$ of the second-order thermal model have a significant effect on $T_{c}$. Since these parameters are not present in the $C$ and $D$ matrices of the first-order model, a large increase in $T_{c}$ was observed in the first-order thermal model. Hence, the inaccuracy is only due to the error in $T_{c}$ estimation. Findings are also supported by several other research studies in the domain. Further, the consideration of thermal capacitance of cell casing, impact of ambient conditions in the second-order model are the reason for high accuracy. Therefore, it could be stated that it is worth investing a few more time, cost and expertise in developing a second-order thermal model for more accurate temperature estimation in LIB. This is especially because of the increasing stringent accuracy requirement of smart BMS typically employed in high-power LIB pack used in EVs and grid-tied energy storage alongside highly sophisticated consumer electronics. The discussed second-order thermal of a single cell can be extended for a LIB pack by integrating the thermal gradient and the impact of peripheral cells alongside optimal placing of temperature sensors inside the battery casing to adjust the ambient temperature parameter value in the model. All these aspects will be considered in our future research.

Author Contributions: Conceptualization, S.S. and S.S.W; methodology, S.S. and A.S.; software, S.S. and A.S.; validation, S.S.; formal analysis, S.S. and A.S; investigation, S.S. and A.S.; resources, V.M. and S.S.W; data curation, V.M.; writing - original draft preparation, S.S. and A.S.; writing-review and editing, A.S. and S.S.W.; visualization, S.S. and A.S.; supervision, S.S.W.; All authors have read and agreed to the published version of the manuscript.

Funding: This research received no external funding.

Conflicts of Interest: The authors declare no conflict of interest

\section{References}

1. Kleiner, J.; Stuckenberger, M.; Komsiyska, L.; Endisch, C. Advanced Monitoring and Prediction of the Thermal State of Intelligent Battery Cells in Electric Vehicles by Physics-Based and Data-Driven Modeling. Batteries 2021, doi:10.3390/batteries7020031.

2. Marcis, V.A.; Kelkar, A.; Williamson, S.S. Electrical circuit modeling of a 18650 lithium-ion cell for charging protocol testing for transportation electrification applications. In Proceedings of the 2020 IEEE Transportation Electrification Conference and Expo, ITEC 2020; 2020.

3. Dao, V.Q.; Dinh, M.-C.; Kim, C.S.; Park, M.; Doh, C.-H.; Bae, J.H.; Lee, M.-K.; Liu, J.; Bai, Z. Design of an Effective State of Charge Estimation Method for a Lithium-Ion Battery Pack Using Extended Kalman Filter and Artificial Neural Network. Energies 2021, doi:10.3390/en14092634.

4. Marcis, V.A.; Praneeth, A.V.J.S.; Patnaik, L.; Williamson, S.S. Analysis of CT-CV Charging Technique for Lithium-ion and NCM 18650 Cells over Temperature Range. In Proceedings of the Proceedings of the IEEE International Conference on Industrial Technology; 2020.

5. Li, W.; Zhu, J.; Xia, Y.; Gorji, M.B.; Wierzbicki, T. Data-Driven Safety Envelope of Lithium-Ion Batteries for Electric Vehicles. Joule 2019, doi:10.1016/j.joule.2019.07.026.

6. Lisbona, D.; Snee, T. A review of hazards associated with primary lithium and lithium-ion batteries. Process Saf. Environ. Prot. 2011, doi:10.1016/j.psep.2011.06.022. 
7. Kong, L.; Li, C.; Jiang, J.; Pecht, M.G. Li-ion battery fire hazards and safety strategies. Energies 2018, doi:10.3390/en11092191.

8. Surya, S.; Marcis, V.; Williamson, S. Core Temperature Estimation for a Lithium ion 18650 Cell. Energies 2020, 14, 87, doi:10.3390/en14010087.

9. Zhu, J.; Sun, Z.; Wei, X.; Dai, H. Battery internal temperature estimation for LiFePO4 battery based on impedance phase shift under operating conditions. Energies 2017, doi:10.3390/en10010060.

10. Sidhu, M.S.; Ronanki, D.; Williamson, S. State of charge estimation of lithium-ion batteries using hybrid machine learning technique. In Proceedings of the IECON Proceedings (Industrial Electronics Conference); 2019.

11. Sidhu, M.S.; Ronanki, D.; Williamson, S. Hybrid State of Charge Estimation Approach for Lithium-ion Batteries using k-Nearest Neighbour and Gaussian Filter-based Error Cancellation. IEEE Int. Symp. Ind. Electron. 2019, 2019-June, 1506-1511, doi:10.1109/ISIE.2019.8781330.

12. Samanta, A.; Chowdhuri, S. Active Cell Balancing of Lithium-ion Battery Pack Using Dual DC-DC Converter and Auxiliary Lead-acid Battery. J. Energy Storage 2021, 33, 102109, doi:10.1016/j.est.2020.102109.

13. Kelkar, A.; Dasari, Y.; Williamson, S.S. A Comprehensive Review of Power Electronics Enabled Active Battery Cell Balancing for Smart Energy Management. In Proceedings of the 2020 IEEE International Conference on Power Electronics, Smart Grid and Renewable Energy, PESGRE 2020; 2020.

14. Samanta, A.; Chowdhuri, S.; Williamson, S.S. Machine Learning-Based Data-Driven Fault Detection/Diagnosis of Lithium-Ion Battery: A Critical Review. Electronics 2021, 10, 1309, doi:10.3390/electronics10111309.

15. Tanim, T.R.; Rahn, C.D.; Wang, C.Y. State of charge estimation of a lithium ion cell based on a temperature dependent and electrolyte enhanced single particle model. Energy 2015, doi:10.1016/j.energy.2014.12.031.

16. Farmann, A.; Sauer, D.U. A study on the dependency of the open-circuit voltage on temperature and actual aging state of lithium-ion batteries. J. Power Sources 2017, doi:10.1016/j.jpowsour.2017.01.098.

17. Zheng, F.; Jiang, J.; Sun, B.; Zhang, W.; Pecht, M. Temperature dependent power capability estimation of lithium-ion batteries for hybrid electric vehicles. Energy 2016, doi:10.1016/j.energy.2016.06.010.

18. Surya, S.; Mn, A. Effect of Fast Discharge of a Battery on its Core Temperature. Int. Conf. Futur. Technol. Control Syst. Renew. Energy, ICFCR 2020 2020, doi:10.1109/ICFCR50903.2020.9249999.

19. Li, Z.; Zhang, J.; Wu, B.; Huang, J.; Nie, Z.; Sun, Y.; An, F.; Wu, N. Examining temporal and spatial variations of internal temperature in large-format laminated battery with embedded thermocouples. J. Power Sources 2013, doi:10.1016/j.jpowsour.2013.04.117.

20. Robinson, J.B.; Darr, J.A.; Eastwood, D.S.; Hinds, G.; Lee, P.D.; Shearing, P.R.; Taiwo, O.O.; Brett, D.J.L. Non-uniform temperature distribution in Li-ion batteries during discharge - A combined thermal imaging, X-ray micro-tomography and electrochemical impedance approach. J. Power Sources 2014, doi:10.1016/j.jpowsour.2013.11.059.

21. Raijmakers, L.H.J.; Danilov, D.L.; Eichel, R.A.; Notten, P.H.L. A review on various temperature-indication methods for Li-ion batteries. Appl. Energy 2019, 240, 918-945, doi:10.1016/j.apenergy.2019.02.078.

22. Pan, Y. wei; Hua, Y.; Zhou, S.; He, R.; Zhang, Y.; Yang, S.; Liu, X.; Lian, Y.; Yan, X.; Wu, B. A computational multi-node electro-thermal model for large prismatic lithium-ion batteries. J. Power Sources 2020, 459, 228070, doi:10.1016/j.jpowsour.2020.228070.

23. Sun, F.; Xiong, R.; He, H.; Li, W.; Aussems, J.E.E. Model-based dynamic multi-parameter method for peak power estimation of lithium-ion batteries. Appl. Energy 2012, doi:10.1016/j.apenergy.2012.02.061.

24. Lu, L.; Han, X.; Li, J.; Hua, J.; Ouyang, M. A review on the key issues for lithium-ion battery management in electric vehicles. J. Power Sources 2013.

25. Ghalkhani, M.; Bahiraei, F.; Nazri, G.A.; Saif, M. Electrochemical-Thermal Model of Pouch-type Lithium-ion Batteries. Electrochim. Acta 2017, doi:10.1016/j.electacta.2017.06.164. 
26. Yang, X.G.; Leng, Y.; Zhang, G.; Ge, S.; Wang, C.Y. Modeling of lithium plating induced aging of lithium-ion batteries: Transition from linear to nonlinear aging. J. Power Sources 2017, doi:10.1016/j.jpowsour.2017.05.110.

27. Allafi, W.; Zhang, C.; Uddin, K.; Worwood, D.; Dinh, T.Q.; Ormeno, P.A.; Li, K.; Marco, J. A lumped thermal model of lithium-ion battery cells considering radiative heat transfer. Appl. Therm. Eng. 2018, doi:10.1016/j.applthermaleng.2018.07.105.

28. Esmaeili, J.; Jannesari, H. Developing heat source term including heat generation at rest condition for Lithium-ion battery pack by up scaling information from cell scale. Energy Convers. Manag. 2017, doi:10.1016/j.enconman.2017.02.052.

29. Arora, S.; Shen, W.; Kapoor, A. Neural network based computational model for estimation of heat generation in LiFePO4 pouch cells of different nominal capacities. Comput. Chem. Eng. 2017, doi:10.1016/j.compchemeng.2017.02.044.

30. Chen, M.; Bai, F.; Song, W.; Lv, J.; Lin, S.; Feng, Z.; Li, Y.; Ding, Y. A multilayer electro-thermal model of pouch battery during normal discharge and internal short circuit process. Appl. Therm. Eng. 2017, doi:10.1016/j.applthermaleng.2017.03.135.

31. Zhao, Y.; Diaz, L.B.; Patel, Y.; Zhang, T.; Offer, G.J. How to Cool Lithium Ion Batteries: Optimising Cell Design using a Thermally Coupled Model. J. Electrochem. Soc. 2019, doi:10.1149/2.0501913jes.

32. Damay, N.; Forgez, C.; Bichat, M.P.; Friedrich, G. Thermal modeling of large prismatic LiFePO4/graphite battery. Coupled thermal and heat generation models for characterization and simulation. J. Power Sources 2015, doi:10.1016/j.jpowsour.2015.02.091.

33. Hu, X.; Liu, W.; Lin, X.; Xie, Y. A Comparative Study of Control-Oriented Thermal Models for Cylindrical Li-Ion Batteries. IEEE Trans. Transp. Electrif. 2019, doi:10.1109/TTE.2019.2953606.

34. Xie, Y.; Li, W.; Hu, X.; Zou, C.; Feng, F.; Tang, X. Novel Mesoscale Electrothermal Modeling for Lithium-Ion Batteries. IEEE Trans. Power Electron. 2020, doi:10.1109/TPEL.2019.2927014.

35. Friesen, A.; Mönnighoff, X.; Börner, M.; Haetge, J.; Schappacher, F.M.; Winter, M. Influence of temperature on the aging behavior of 18650-type lithium ion cells: A comprehensive approach combining electrochemical characterization and post-mortem analysis. J. Power Sources 2017, doi:10.1016/j.jpowsour.2016.12.040.

36. Fan, Y.; Bao, Y.; Ling, C.; Chu, Y.; Tan, X.; Yang, S. Experimental study on the thermal management performance of air cooling for high energy density cylindrical lithium-ion batteries. Appl. Therm. Eng. 2019, doi:10.1016/j.applthermaleng.2019.03.157.

37. Saw, L.H.; Poon, H.M.; Thiam, H.S.; Cai, Z.; Chong, W.T.; Pambudi, N.A.; King, Y.J. Novel thermal management system using mist cooling for lithium-ion battery packs. Appl. Energy 2018, doi:10.1016/j.apenergy.2018.04.042.

38. Liu, B.; Yin, S.; Xu, J. Integrated computation model of lithium-ion battery subject to nail penetration. Appl. Energy 2016, doi:10.1016/j.apenergy.2016.08.101.

39. Doyle, M. Modeling of Galvanostatic Charge and Discharge of the Lithium/Polymer/Insertion Cell. J. Electrochem. Soc. 1993, doi:10.1149/1.2221597.

40. Xiao, Y.; Fahimi, B. State-space based multi-nodes thermal model for lithium-ion battery. In Proceedings of the 2014 IEEE Transportation Electrification Conference and Expo: Components, Systems, and Power Electronics - From Technology to Business and Public Policy, ITEC 2014; 2014.

41. Tian, N.; Fang, H.; Wang, Y. 3-D Temperature Field Reconstruction for a Lithium-Ion Battery Pack: A Distributed Kalman Filtering Approach. IEEE Trans. Control Syst. Technol. 2019, doi:10.1109/TCST.2017.2779434.

42. Ruan, H.; Jiang, J.; Sun, B.; Gao, W.; Wang, L.; Zhang, W. Online estimation of thermal parameters based on a reduced wide-temperature-range electro-thermal coupled model for lithium-ion batteries. J. Power Sources 2018, doi:10.1016/j.jpowsour.2018.03.075.

43. Forgez, C.; Vinh Do, D.; Friedrich, G.; Morcrette, M.; Delacourt, C. Thermal modeling of a cylindrical LiFePO4/graphite 
lithium-ion battery. J. Power Sources 2010, 195, 2961-2968, doi:10.1016/j.jpowsour.2009.10.105.

44. Dees, D.W.; Battaglia, V.S.; Bélanger, A. Electrochemical modeling of lithium polymer batteries. J. Power Sources 2002, doi:10.1016/s0378-7753(02)00193-3.

45. Lin, X.; Perez, H.E.; Siegel, J.B.; Stefanopoulou, A.G.; Li, Y.; Anderson, R.D.; Ding, Y.; Castanier, M.P. Online parameterization of lumped thermal dynamics in cylindrical lithium ion batteries for core temperature estimation and health monitoring. IEEE Trans. Control Syst. Technol. 2013, 21, 1745-1755, doi:10.1109/TCST.2012.2217143.

46. Choi, J.W.; Aurbach, D. Promise and reality of post-lithium-ion batteries with high energy densities. Nat. Rev. Mater. 2016.

47. Yang, F.; Wang, D.; Zhao, Y.; Tsui, K.L.; Bae, S.J. A study of the relationship between coulombic efficiency and capacity degradation of commercial lithium-ion batteries. Energy 2018, doi:10.1016/j.energy.2017.12.144.

48. Wang, Q.; Zhao, X.; Ye, J.; Sun, Q.; Ping, P.; Sun, J. Thermal response of lithium-ion battery during charging and discharging under adiabatic conditions. J. Therm. Anal. Calorim. 2016, doi:10.1007/s10973-015-5100-4.

49. Patnaik, L.; Williamson, S. A Five-Parameter Analytical Curvefit Model for Open-Circuit Voltage Variation with State-of-Charge of a Rechargeable Battery. In Proceedings of the Proceedings of 2018 IEEE International Conference on Power Electronics, Drives and Energy Systems, PEDES 2018; 2018.

50. Bryden, T.S.; Dimitrov, B.; Hilton, G.; Ponce de León, C.; Bugryniec, P.; Brown, S.; Cumming, D.; Cruden, A. Methodology to determine the heat capacity of lithium-ion cells. J. Power Sources 2018, doi:10.1016/j.jpowsour.2018.05.084.

51. Surya, S.; Channegowda, J.; Datar, S.D.; Jha, A.S.; Victor, A. Accurate battery modeling based on pulse charging using MATLAB / Simulink. In Proceedings of the 9th IEEE International Conference on Power Electronics, Drives and Energy Systems, PEDES 2020; 2020.

52. Lin, C.; Yu, Q.; Xiong, R.; Wang, L.Y. A study on the impact of open circuit voltage tests on state of charge estimation for lithium-ion batteries. Appl. Energy 2017, doi:10.1016/j.apenergy.2017.08.124.

53. Bernardi, D.; Pawlikowski, E.; Newman, J. GENERAL ENERGY BALANCE FOR BATTERY SYSTEMS. In Proceedings of the Electrochemical Society Extended Abstracts; 1984.

54. Greco, A.; Cao, D.; Jiang, X.; Yang, H. A theoretical and computational study of lithium-ion battery thermal management for electric vehicles using heat pipes. J. Power Sources 2014, doi:10.1016/j.jpowsour.2014.02.004.

55. Rao, Z.; Wang, S.; Zhang, G. Simulation and experiment of thermal energy management with phase change material for ageing LiFePO4 power battery. Energy Convers. Manag. 2011, doi:10.1016/j.enconman.2011.07.009.

56. Xie, Y.; Shi, S.; Tang, J.; Wu, H.; Yu, J. Experimental and analytical study on heat generation characteristics of a lithium-ion power battery. Int. J. Heat Mass Transf. 2018, doi:10.1016/j.ijheatmasstransfer.2018.02.038.

57. Chen, L.; Hu, M.; Cao, K.; Li, S.; Su, Z.; Jin, G.; Fu, C. Core temperature estimation based on electro-thermal model of lithium-ion batteries. Int. J. Energy Res. 2020, 44, 5320-5333, doi:10.1002/er.5281.

58. Surya, S.; Bhesaniya, A.; Gogate, A.; Ankur, R.; Patil, V. Development of thermal model for estimation of core temperature of batteries. Int. J. Emerg. Electr. Power Syst. 2020, doi:10.1515/ijeeps-2020-0070.

59. Surya, S.; Patil, V. Cuk Converter as an Efficient Driver for LED. In Proceedings of the 4th International Conference on Electrical, Electronics, Communication, Computer Technologies and Optimization Techniques, ICEECCOT $2019 ; 2019$.

60. Surya, S.; Marcis, V.; Williamson, S. Core Temperature Estimation for a Lithium ion 18650 Cell. Energies 2020, doi:10.3390/en14010087.

61. Lin, X.; Stefanopoulou, A.G.; Perez, H.E.; Siegel, J.B.; Li, Y.; Anderson, R.D. Quadruple adaptive observer of the core temperature in cylindrical Li-ion batteries and their health monitoring. Proc. Am. Control Conf. 2012, 578, 578-583, doi:10.1109/acc.2012.6315386.

62. Sun, J.; Wei, G.; Pei, L.; Lu, R.; Song, K.; Wu, C.; Zhu, C. Online internal temperature estimation for lithium-ion batteries based on Kalman filter. Energies 2015, 8, 4400-4415, doi:10.3390/en8054400. 
63. Mochnáč, J.; Marchevský, S.; Kocan, P. Bayesian filtering techniques: Kalman and extended Kalman filter basics. In Proceedings of the Proceedings of 19th International Conference Radioelektronika 2009, RADIOELEKTRONIKA '09; 2009.

64. Hwang, P.Y.C. introduction to Random signals and Applied Kalman Filtering with MATLAB exercises. J. Chem. Inf. Model. 2013.

65. Kim, Y.; Bang, H. Introduction to Kalman Filter and Its Applications. In Introduction and Implementations of the Kalman Filter; 2019.

66. Plett, G. Battery Management Systems, Volume II: Equivalent-Circuit Methods; Artech, 2015; ISBN 9781630810283.

67. Patnaik, L.; Praneeth, A.V.J.S.; Williamson, S.S. A Closed-Loop Constant-Temperature Constant-Voltage Charging Technique to Reduce Charge Time of Lithium-Ion Batteries. IEEE Trans. Ind. Electron. 2019, doi:10.1109/TIE.2018.2833038.

68. Williamson, S.; Vincent, D.; Praneeth, A.; Sang, P.H. Charging Strategies for Electrified Transport. In Advances in Carbon Management Technologies; 2020. 